\title{
EN 14103 adjustments for biodiesel analysis from different raw materials, including animal tallow containing C17
}

\author{
Fabrícia Gasparini ${ }^{1}$, José Renato de O. Lima ${ }^{1}$, Yussra A. Ghani ${ }^{1}$, Rafael R. Hatanaka ${ }^{1}$, \\ Rodrigo Sequinel $^{1}$, Danilo L. Flumignan ${ }^{1,2}$, José Eduardo de Oliveira ${ }^{1 *}$ \\ ${ }^{1}$ Center for Monitoring and Research of the Quality of Fuels, Biofuels, Crude Oil and Derivatives - \\ CEMPEQC - Organic Chemistry Department, Institute of Chemistry, , \\ São Paulo State University - UNESP, R. Prof. Francisco Degni s/n, Quitandinha, 14800-900, Araraquara, \\ São Paulo, Brazil. \\ ${ }^{2}$ São Paulo Federal Institute of Education, Science and Technology - IFSP, Campus Avançado Matão, Rua José \\ Bonifácio, 1176, Centro, 15990-040, Matão, São Paulo, Brazil \\ *Corresponding author: Tel: +55 163301 9666, Fax: +55 163301 9693, E-mail: \\ jeduardo.unesp@yahoo.com.br
}

\begin{abstract}
EN 14103 is suitable to quantify the ester content in biodiesel free of heptadecanoate ester (C17:0), because it is employed as internal standard (IS). But EN 14103 cannot be applied to the analysis of tallow biodiesel because C17:0 is found in animal fats. This work proposes an improved method, based on EN 14103 capable to determine ester content in tallow biodiesel. Twenty samples from tallow, soybean, babassu and palm biodiesels and its blends were used to carry out the analysis. Chromatograms of ethylic biodiesel were analyzed using separately methylic and ethylic C17:0 (IS). The results showed that some peaks from tallow biodiesel coeluted with both IS peaks, confirming the impossibility to quantify ethylic esters using those standards. Despite this, in all analyzed samples it was observed a constant relationship between two neighbor peaks occurring naturally in the tallow samples. The rate between them was measured and applied as a correction factor to measure the real influence, caused on methylic C17:0 IS by natural C17:0. As a result, the original equation from EN 14103, modified by the introduction of a correction factor $(F)$, resulted in another equation more adequate to analyze the ester content in tallow biodiesel and its blends. Pure tallow biodiesel presented ester content around $4.3 \%$ greater, when quantified using the equation containing the correction factor, instead of the original equation.
\end{abstract}

Keywords: EN 14103, Tallow Ethylic Biodiesel, Heptadecanoate.

\section{Introduction}

Biodiesel is a biofuel produced worldwide from several oils and fats, obtained from both vegetable and animal sources. This fuel is capable to work in diesel engines and hence be mixed to mineral diesel or replace it completely [1, 2]. Many countries around the world produce, import and/or export fuels, thus it is necessary to promote the internationalization of standards that specify the methods of analysis and maximum/minimum limits for quality parameters in order to allow a technically effective commerce worldwide. Technical data are used to set those limits. To harmonize the biodiesel specifications, the limits set in a global standard need to be carefully considered, since specification limits have arisen based in different utilization contexts [3]. Currently the evaluation of the biodiesel quality is a global concern. In this way experts from standards elaboration organizations from Brazil, United States and European Union, have participate of meetings with the objective of discuss standards for the evaluation of biodiesel quality.

The ester content is the most important biodiesel quality parameter, since the ester is the biodiesel itself. EN 14103 is a standard that evaluates chromatographically the ester content of biodiesel [4] and was developed for analysis of methylic biodiesel obtained from vegetable oils predominantly found in Europe. So this standard contemplates only methyl biodiesel obtained from oils which composition has the majority of carbon chains from C14:0 to C24:1 and which does not contain C17:0 in its composition. The wide feedstock diversity used to 
produce biodiesel around the world [5] makes the use of EN 14103 inadequate not only when we consider the composition of the oils, but also the choice of applied alcohol. That standard can be useful to measure the ester content of soybean, sunflower, rapeseed and other methylic biodiesels, but do not makes mention to ethylic biodiesel and is not capable to measure the ester content of tallow biodiesel itself or when present in blends.

Biodiesel from tallow has C17:0 in its composition. This represents a major concern in Brazil in relation to assessment of its quality, once biodiesel from tallow is already inserted in the national and international market [6].

One Brazilian solution to overcome the limitations of EN 14103 was the development of NBR 15764 [7]. This standard allows biodiesel quantification produced from different types of oils fats and alcohols, using external standardization. However this method has a weakness even more critical when compared with all the EN 14103 limitations. The NBR 15764 states the use of chloroform as solvent. This solvent is incompatible with the (GC-FID) detector since it promotes corrosion of the detector during use with the consequent loss of sensitivity. Compounds containing chlorine atoms in its structure, when burned in the detector flame, produce hydrochloric acid, promoting the corrosion of the detector, and can infer the reliability of analysis results [8].

A large number of biodiesels from different raw materials are produced around the world and being marketed pure or as blends. Tallow biodiesel is possibly present in those blends. The possibility of using ethanol as reactant is another important factor that must to be taken in account because its choice for biodiesel preparation makes the analysis of ester content particularly impaired.

Thus, this paper proposes an evaluation and adjustment of the EN 14103 analytical conditions in order to quantify adequately total ester content not only from methylic but also ethylic biodiesel, even in matrices containing the C17:0 in its composition, taking in to account that the global trends are the commercialization of biodiesel "blends". The biodiesels used in this approach were prepared from soybean, palm, babassu oils and bovine tallow, the mostly used raw materials in Brazil.

\section{Methodology}

\subsection{Raw materials, solvents and standards}

Four different types of raw materials were used: soybean, palm, babassu oil and bovine tallow. Industrialized oils purchased in local shops were used and the tallow experienced craft process of grinding and frying before being used. Anhydrous ethanol was synthesis grade (Synth, lot 118784) Internal standards (IS) were methyl myristate (C14:0), methyl nervonate (C24:1), methylic and ethylic heptadecanoate (C17:0) (Nu-Chek, >99\%). Heptane (Vetec0803307) HPLC grade was used for sample dilutions.

\subsection{Biodiesel}

Eight ethylic biodiesels were prepared, by transesterification, two from each oil and fat selected. The preparations were performed in two conditions: varying the key variables responsible for the total or partial conversion into esters. Four biodiesel were made under conditions that present high conversion rate with the heating time of $120 \mathrm{~min}$, molar ratio alcohol/oil 9:1 and 1\% of catalyst. The other four biodiesel, were made under conditions to present low conversion rates with heating time of $30 \mathrm{~min}$, molar ratio alcohol/oil 6:1 and 0,3\% 
of catalyst. All biodiesels were prepared at $75{ }^{\circ} \mathrm{C}$, next to the boiling point of ethanol. The choice of conditions was performed according to a review of the literature [9-12]. The transesterification reactions were performed using ethanol and catalyzed by sodium hydroxide.

\subsection{Blends}

The eight biodiesel were mixed forming blends with different levels of esters, totalizing 20 samples. $10 \mathrm{~mL}$ of each sample was prepared containing equal volumes of each biodiesel with the aid of a micropipette.

\subsection{Analysis of samples}

The quantifications of ester content in biodiesel samples were performed, in triplicates, according to EN 14103 [Fat and oil derivatives - Fatty Acid Methyl Esters (FAME) Determination of Ester and linolenic acid methyl esters contents] in a Shimadzu GC 2010 gas chromatograph with flame ionization detector (GC-FID). The chromatograph was configured with injector in split mode coupled to auto-sampler AOC 5000 for liquid samples. EN 14103 establishes the chromatographic conditions used in the quantification of fatty acid esters: sample injection volume $=1 \mathrm{~mL}$, split $=1: 20$, injector and detector temperatures $=250{ }^{\circ} \mathrm{C}$, isothermal oven temperature $=210{ }^{\circ} \mathrm{C}$, pressure of helium carrier gas $=83 \mathrm{kPa}$ due to "split" or adjusted to visualize clearly the peak of the methyl standard C24:1. Because of difficulties in visualize clearly the peak of the methyl standard C24:1, under isothermal conditions, in this study the isothermal condition of the oven was replaced by programmed temperature conditions. $120^{\circ} \mathrm{C}$ for 2 minutes, heating rate $10^{\circ} \mathrm{C} / \mathrm{min}$ to a temperature of $180{ }^{\circ} \mathrm{C}$, where it remained for three minutes, new heating rate of $5{ }^{\circ} \mathrm{C} / \mathrm{min}$ until $240{ }^{\circ} \mathrm{C}$ where it remained for 10 minutes. The capillary column used was a Restek-Carbowax $30 \mathrm{~m}$ long, $0.25 \mathrm{~mm}$ internal diameter and $0.25 \mathrm{~mm}$ stationary phase thickness.

\subsection{Quantification of ester contents}

$20 \mathrm{mg} / \mathrm{mL}$ stock solutions of methyl myristate (C14:0) and methyl nervonate (C24:1) standards were prepared, while methylic and ethylic heptadecanoate standards were prepared in $10 \mathrm{mg} / \mathrm{mL}$ stock solutions. Methyl esters standards C14:0 and C24:1 were used to identify the range of integration. In addition, we used the methylic and ethylic (C17:0) esters as IS. The ester contents were obtained by integrating the peak areas ranging from C14:0 to C24:0 and subtracting heptadecanoate area, as showed in Eq. (1).

$\%$ Ester $=\frac{\Sigma_{\mathrm{A}}-A_{C 17 I S}}{A_{C 17 I S}}+\frac{\left(C_{E I} * V_{E I}\right)}{m} * 100$

where:

$\sum A=$ sum of areas of all peaks ranging from C14:0 and C24:0

$\boldsymbol{A}_{\boldsymbol{C 1 7} \text { IS }}=$ C17:0 IS area

$C_{E I}=$ concentration $(\mathrm{mg} / \mathrm{mL})$ of $\mathrm{C} 17: 0$ solution

$V_{E I}=$ volume of $\mathrm{C} 17: 0$ solution added to sample

$m=$ mass of the sample (mg). 


\section{Results and Discussion}

\subsection{EN 14103 for ethylic biodiesel}

To quantify ethyl esters in biodiesel according to EN 14103, a study was conducted using methyl and ethyl standards under the conditions described in 2.4. The retention times (RT) of methyl and ethyl standards were: methyl C14:0 (8.6 min), ethyl C14:0 (9.2 min), methyl C24:1 (26.5 min) and ethyl C24:1 (27.2 min). From these results is possible to note that there is only a small variation on the beginning and the end of integration intervals. It was not observed any new peak in both intervals; hence the ester quantification accuracy will be not affected by using methyl standards to analyze ethyl esters. The 20 samples of biodiesel used in this study were quantified using the method 1 (EN 14103) and method 2 (conditions of EN 14103 unchanged, except for the integration of the ester peaks performed using the ethyl standards RT). The results were compared using the Student $\mathrm{T}$ test. The value of t-calculated to a limit of $95 \%$ of confidence was 0.81 while the theoretical value is 1.98 , meaning that there is no significant difference between the two methods of quantification. Furthermore, in both cases the ester content results variation were below the method repeatability, that is 1.6 $\% \mathrm{~m} / \mathrm{m}$.

\subsection{EN 14103 applied to biodiesel containing C17}

Biodiesels containing heptadecanoate (C17:0) in their composition, (e.g. beef tallow), needs two chromatographic runs to be analyzed; one with IS and another without the addition of the C17:0 IS. The reason for this is that C17:0 IS is necessary to assist the quantification, but if C17:0 is already present in the sample (e.g. tallow biodiesel) the C17:0 of the standard coelutes and consequently presents an area bigger than that corresponds to itself. Looking at the chromatogram of a sample without C17:0 IS (Figure 1), it is possible to found the co-eluted peaks (A when using methylic IS and B if it is used ethylic IS). Therefore it is necessary to run another chromatogram without IS. After that, the peak area at the same retention time of C17:0 IS must be subtracted from it and included in the total peaks sum.

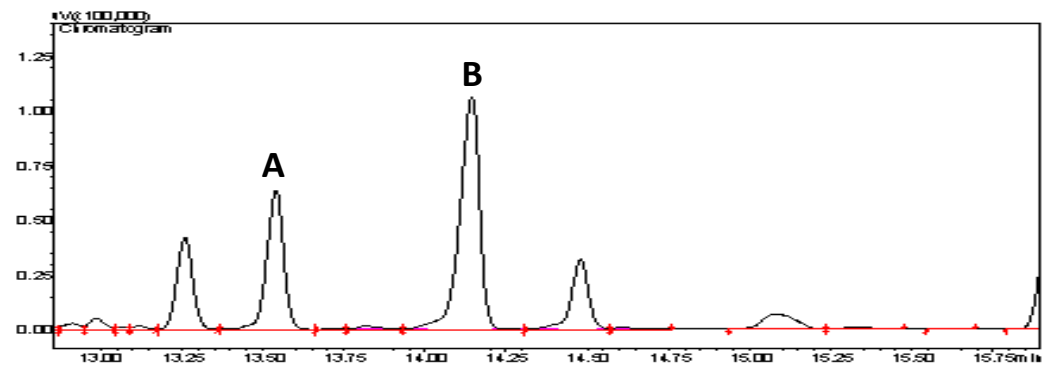

Fig. 1. Chromatogram window of a biodiesel blend showing the peaks $A$ and B (A co-elutes with methylic C17:0 and B co-elutes with ethylic C17:0

During the development of the procedure, to overcome the need of two chromatographic runs, firstly $y_{2}$ two chromatograms of ethyl and methyl C17:0 standards were obtained. The RTs were 13.5 min for methylic and 14.2 min for ethylic standards. The biodiesels of soybean, palm and babassu were diluted in heptane (without addition of C17:0 IS) in order to verify the occurrence of peaks in the RT 13.5 and $14.2 \mathrm{~min}$. These chromatographic runs were successful, since they did not show any peaks in the regions of those RT. This fact showed the possibility of using both IS for ester quantification in the studied biodiesels samples.

Beef tallow biodiesel was then diluted with heptane and its chromatogram was compared with C17:0 standards methyl and ethyl chromatograms. Both, the methyl and ethyl standards coelute with peaks of esters present in tallow biodiesel (Fig. 2). 


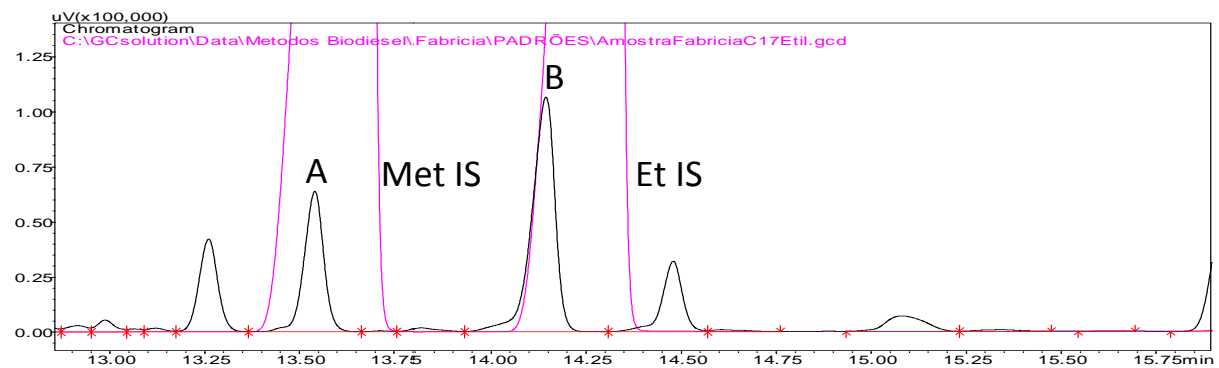

Fig. 2. Chromatogram window showing methyl (Met IS - black colour) and ethyl (Et IS - pink colour) IS peaks that co-elutes with A and B peaks from tallow biodiesel, respectively.

Thus, it is not possible to quantify correctly the ester content in tallow biodiesel or its blends using methylic or ethylic C17:0 IS. But, an accurate analysis of the chromatograms, allow to perceive a constant ratio between the two peaks areas $A$ and $B$, that co-elute with C17:0 IS. To confirm how useful and confident would be this relationship between A and B peak area, a C17 external calibration curve was performed intending to support the quantification of C17 from samples. A seven point curve was produced using concentrations from 0.5 to 5 percent of ethylic C17 in heptane. Chromatographic conditions were similar to those used for ester content analysis official method EN 14103. Equation 2 is the curve calibration equation used to calculate A and B peak areas of the samples $\left(\mathrm{R}^{2}=0.9999\right)$. After that, seven biodiesel samples were analyzed from which five were mix of soybean and commercial beef tallow biodiesel and two of them were samples were pure biodiesel of soybean and beef tallow.

$$
\%_{C 17}=A_{\text {peak }} * 1,24638^{-7}+1,59447^{-2}
$$

Table 1 presents the percentage of tallow biodiesel in blends, C17 content into each sample and the ratio $\mathrm{A} / \mathrm{B}$ results for every blend. The $\mathrm{A}$ and $\mathrm{B}$ peaks were quantified using the external calibration curve.

Table 1. Blends of tallow biodiesel with soybean, the \% C17 found and ratio A/B peak.

\begin{tabular}{lccccccc}
\hline & $\begin{array}{c}\text { Mix 0 } \\
\mathbf{( 0 \% )}\end{array}$ & $\begin{array}{c}\text { Mix 1 } \\
\mathbf{( 5 \% )}\end{array}$ & $\begin{array}{c}\text { Mix 2 } \\
\mathbf{( 2 5 \% )}\end{array}$ & $\begin{array}{c}\text { Mix 3 } \\
\mathbf{( 4 5 \% )}\end{array}$ & $\begin{array}{c}\text { Mix 4 } \\
\mathbf{( 6 5 \% )}\end{array}$ & $\begin{array}{c}\text { Mix 5 } \\
\mathbf{( 8 5 \% )}\end{array}$ & $\begin{array}{c}\text { Mix 6 } \\
(\mathbf{1 0 0 \% )}\end{array}$ \\
\hline $\begin{array}{l}\text { Tallow } \\
\text { Biodiesel }\end{array}$ & 0 & 5 & 25 & 45 & 65 & 85 & 100 \\
\hline $\begin{array}{l}\text { Soybean } \\
\text { Biodiesel }\end{array}$ & 100 & 95 & 75 & 65 & 45 & 15 & 0 \\
\hline \%C17 & - & 0.021 & 0.028 & 0.328 & 0.0386 & 0.0451 & 0.049 \\
\hline $\begin{array}{l}\text { A/B } \\
\text { ratio }\end{array}$ & - & 0.15 & 0.30 & 0.41 & 0.44 & 0.46 & 0.46 \\
\hline
\end{tabular}

In the Graph 1 we can observe the behavior of A/B ratio related to $\mathrm{C} 17$ percentage. They are much correlated, especially when tallow biodiesel percentage is above fifty percent. In other hand, for pure tallow biodiesel or rich blends A/B variation curve is practically stable what shows that is possible to use an average $\mathrm{A} / \mathrm{B}$ ratio value in order to correct the ester content analysis results without needs to proceed another GC analysis. 


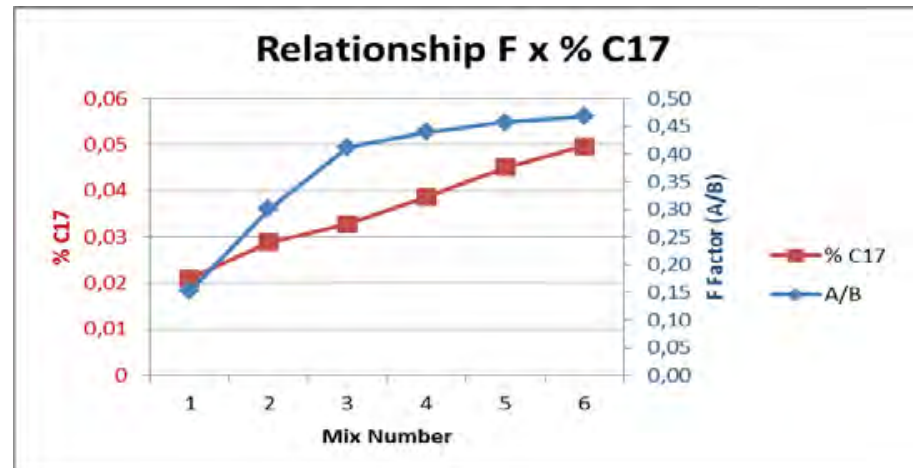

Graph 1. Behavior of A/B ratio related to $C 17$ percentage in samples

Taking into account the relationship between the A and B peak areas and C17 percentage of pure beef tallow biodiesel (Graph 1), it was possible to establish a correctional factor that should be introduced into original formula of EN 14103 for quantify the ester content. The value adopted was the average of A/B ratio considering samples Mix 3, Mix 4, Mix 5 and Mix 6 . That way we recommend to use 0,45 as a correctional factor " $F$ ".

For this, the area of methylic C17:0 IS used in Eq. 1 was replaced by other term containing $F$ (A/B). In this new term, the methylic C17:0 IS area was subtracted of: ethylic C17:0 IS area (RT 14.2 min.) multiplied by F. Moreover, this last product represents the peak co-eluted with methylic IS, so it was added to total peak sum. Thus, for quantification of samples containing beef tallow biodiesel, the Eq.(1), was replaced by Eq. (3).

In Eq. (2) the $\boldsymbol{A}_{\boldsymbol{C 1 7} \text { IS }}$ was replaced by $\boldsymbol{A}_{\boldsymbol{C 1 7} \text { IS }}-\left(\boldsymbol{A}_{\boldsymbol{C 1 7} \text { et }} * \boldsymbol{F}\right)$.

$\%$ Ester $=\frac{\left[\left(\Sigma_{\mathrm{A}}+\left(A_{C 17 e t} * F\right)\right)-\left(A_{C 17 I S}-\left(A_{C 17 e t} * F\right)\right)\right]}{A_{C 17 I S}-\left(A_{C 17 e t} * F\right)}+\frac{\left(C_{E I} * V_{E I}\right)}{m} * 100$

where:

$A_{C 17 E t}=$ Area of C17:0 ethylic present in the sample.

$F=$ Correction factor

The mean value of $\mathrm{F}$ found was applied in the further experiments. Table 2 shows the study of $\mathrm{F}$ behavior to several samples of tallow biodiesel pure and its blends with soybean, babassu and palm oil biodiesel. Those samples were designed to present different ester levels intending to confirm F efficiency when applied to any matrix.

Although the t test did not show significant differences (t-calculated 0.78 and theoretical 1.03) for the sample of beef tallow biodiesel when using Eq. (1) and (3), the difference between results reach value bigger than the repeatability $(1.6 \% \mathrm{~m} / \mathrm{m})$ of the method. A difference of $2.5 \%$ for beef tallow biodiesel was detected in its ester content. This difference is bigger than C17 ester content found by some authors [13] (1,7\% of C17), however the complex biosynthesis of fatty acid can provide different level of this bioproducts available on fatty issue. Other works [6] presumes levels that can reach almost 5\% of C17. 
Table 2. Study of F behavior in different tallow biodiesel samples and blends.

\begin{tabular}{lcc}
\hline $\begin{array}{c}\text { Samples } \\
\text { containing tallow }\end{array}$ & $\begin{array}{c}\text { \% ester no using } \\
\text { F correction }\end{array}$ & $\begin{array}{c}\text { \% ester with F } \\
\text { correction }\end{array}$ \\
\hline $\mathrm{Tb}^{\mathrm{a}}$ & 7,4 & 7,5 \\
\hline $\mathrm{Tb}^{\mathrm{c} / \mathrm{a}}$ & 46,3 & 46,5 \\
\hline $\mathrm{Tb}^{\mathrm{d} / \mathrm{a}}$ & 52,8 & 53,0 \\
\hline $\mathrm{Tb}^{\mathrm{e} / \mathrm{a}}$ & 49,6 & 49,7 \\
\hline $\mathrm{Tb}^{\mathrm{b}}$ & 91,6 & 93,1 \\
\hline $\mathrm{Tb}^{\mathrm{c} / \mathrm{b}}$ & 96,8 & 98,9 \\
\hline $\mathrm{Tb}^{\mathrm{d} / \mathrm{b}}$ & 97,1 & 99,2 \\
\hline $\mathrm{Tb}^{\mathrm{e} / \mathrm{b}}$ & 94,2 & 96,3
\end{tabular}

a) Tallow biodiesel type low ester content; b) Tallow biodiesel type high ester content; c) soybean biodiesel type; d) babassu biodiesel; e) palm oil biodiesel.

In this sense, it was necessary to identify what substance is assigned to A peak. Since B is heptadecanoate. Some studies [6,13] concludes that A peak can be isomers of C17:0, like heptadecenoate and/or branched C17:0 fatty acid esters. Therefore, is comprehensible the fact of $\mathrm{A}$ and $\mathrm{B}$ present a regular proportion.

Within this context, we note that the difficulty in using the EN 14103 to quantify the levels of esters in biodiesel produced from different matrices was overcome. These achievements support us to propose the results of this work as a new standard, since the NBR 15764 is not suitable for quantifying the ester content in biodiesel.

\section{Conclusions}

Through an evaluation and adaptation of EN 14103, the limitations on feedstock and alcohol used in the production of biodiesel were effectively circumvented. Analyses performed using methyl and ethyl IS showed that there were no significant differences when comparing the results of ester content using both types of standards (methods 1 and 2). So ethyl and methyl biodiesel can be quantified using both methyl and ethyl IS using EN 14103 conditions.

For the ester quantification of ethyl beef tallow biodiesel, is necessary to introduce a correction factor (F) in the original equation of EN 14103 (Eq. 3), keeping the methylic standard C17:0 established by original method. In the cases when methylic beef tallow biodiesels are analyzed, it is necessary to do another few adjusts, however it should be used a similar procedure. Thus, it was possible to quantify adequately all peaks related to the esters in beef tallow ethylic biodiesel. In the other samples (soy, sunflower, rapeseed, babassu and palm biodiesels), there is no problem in using Eq. 3 because the final result will be equal. We recommend a study about composition of other fats in order to confirm existence and proportionality between A and B peaks.

\section{References}

[1] White Paper. Internationally compatible biofuel Standards. Tripartite task force Brazil, European Union \& United States of America. 95, 2007, f. 31. 
[2] Lima, J. R. O.; Silva, R. B.; Silva, C. C. M.; Santos, L. S. S.; Santos-Junior, J. R.; Moura E. M.; Moura, C. V. R. Biodiesel de babaçu (Orbignya SP.) obtido por via etanólica. Química Nova, v. 30, n. 3, 2007, pp. 600-603.

[3] Alleman, T.L. Harmonization of biodiesel specifications, Lipid Technology, v. 20, n. 02, 2008, pp. 40-42.

[4] EN 14103 DEUTSCHES INSTITUT FÜR NORMUNG. EN 14103: fat and oil derivatives - fatty acid methyl esters (FAME) - determination of ester and Linolenic acid methyl ester contents. Germany, 2003. 10 p.

[5] Atadashi, I.M.; Aroua, M.K.; Aziz, A.A. High quality biodiesel and its diesel engine application: A review. Renewable and Sustainable Energy Reviews, v.14, 2010, pp. 1999-2008.

[6] MCT - AGÊNCIA NACIONAL DO PETRÓLEO, GÁS NATURAL E BIOCOMBUSTÍVEIS. Superintendência de Biocombustíveis e de Qualidade de Produtos. Centro de Pesquisas e Análises Tecnológicas. Comparação inter-laboratorial para análise de teor de ésteres em biodiesel de sebo bovino. Rio de Janeiro, 2009. 25 f.

[7] ASSOCIAÇÃO BRASILEIRA DE NORMAS TÉCNICAS. Biodiesel - determinação do teor total de ésteres por cromatografia gasosa. Homologação e publicação de normas brasileiras. Disponível em: $<$ http://www.abnt.org.br/imagens/normalizacao_homologacao/lista_de_publicacao__2009.10.06_a_2009.10.30.pdf>. Acesso em: 05 abr. 2010.

[8] Ciola, R. Fundamentos da Cromatografia a Gás. São Paulo: Edgard Blucher, 1985.

[9] Tippayawong, N.; Kongjareon, E.; Jompakdee, W. Ethanolisys of soybean oil into biodiesel: process optimization via central composite design. Journal of Mechanical Science and Technology, v. 19, n. 10, 2005, pp. 1902-1909.

[10]Encimar, J. M.; Gonzlez, J. F.; Rodriguez, J. J.; Tejedor, A. Biodiesel fuels from vegetable oils: transesterification of Cynara cardunculus L. oils with ethanol. Energy and Fuels, v.16, n. 2, 2002, pp. 443-450.

[11]BRASIL. Portal do Biodiesel. Biogasolina: produção de éteres e ésteres da glicerina. Disponível em: <http://www.biodiesel.gov.br/docs/congressso2006/CoProdutos/Biogasolina3.pdf> Acesso em: 20 fev. 2010.

[12]Rashid, U.; Anwar, F.; Knothe, G. Evaluation of biodiesel obtained from cottonseed oil. Fuel Processing Technology, v. 90, n. 9, 2009, pp. 1157-1163.

[13]CUNHA, M. E. Caracterização de biodiesel produzido com misturas binárias de sebo bovino, gordura de frango e óleo de soja. Dissertação de mestrado. Universidade Federal do Rio Grande do Sul, Porto Alegre, 2008, p. 55. 